\title{
Ampelographic and Molecular Characterisation of Aglianico Accessions (Vitis vinifera L.) Collected in Southern Italy
}

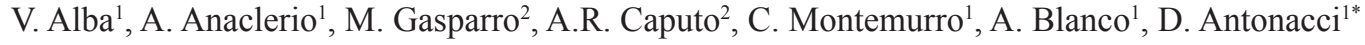 \\ (1) Department of Agro-forestry and Environmental Biology and Chemistry, Section of Genetics and Breeding, University of \\ Bari, Via Amendola 165/A, 70126, Bari, Italy \\ (2) CRA-UTV, Agricultural Research Council - Research Unit for table grapes and wine growing in Mediterranean environment, \\ Via Casamassima 148, 70010, Turi (BA), Italy
}

Submitted for publication: January 2011

Accepted for publication: May 2011

Key words: Vitis vinifera L., Aglianico, ampelography, molecular markers

\begin{abstract}
To characterise 31 different Aglianico accessions randomly collected in Southern Italy, 30 ampelographic descriptors, 13 SSRs and 10 AFLP primer combinations were analysed. An appreciable variation of ampelographic descriptors was revealed mainly by mature leaf traits, while very few variations were recorded for shoot and berry traits. Similarly, all SSR loci revealed molecular monomorphism and AFLPs with a very high genetic similarity (Dice coefficient) among all the accessions considered. One of the aims of this study was to clarify the genetic assessment of Aglianico Nero and Aglianico del Vulture Nero, since they are registered as two different cultivars with distinct varietal codes at the Italian Register of Grape Varieties. Registered Aglianico Nero and Aglianico del Vulture Nero were included in the analyses, compared and used as reference material. Our plants showed that all the accessions tested, independent from the biotype, and the two registered cultivars belong to the same genotype, suggesting that, as reported by the Vitis International Variety Catalogue, a case of synonymy occurred between Aglianico Nero and Aglianico del Vulture Nero. These cultivars could therefore be considered as a single cultivar. Moreover, the AFLP data revealed a partial match between morphological and molecular data, showing that the AFLP molecular method was able to discriminate between different accessions belonging to the same cultivar.
\end{abstract}

\section{INTRODUCTION}

Grapevine has been cultured worldwide for a very long time and its long history of domestication has led to the diffusion of many biotypes and cultivars. This has resulted in a great genetic variability in germplasm that has often allowed misidentification and cases of homonymy and synonymy (Vignani et al., 2002). Historical evidence and information, combined with morphological data (ampelography), have frequently been used to characterise cultivars and to define relationships between them. However, conclusions on these bases are frequently questioned, leading to mistakes in cultivar identification, suggesting verification at the genetic level (Labra et al., 2004). To this end, polymerase chain reaction (PCR)-based DNA marker technologies have been widely applied in many crop species. In grapevine, SSRs (Simple Sequence Repeats) have been employed efficiently for cultivar identification (Bowers et al., 1999; Crespan, 2003; This et al., 2004; Jahnke et al., 2009; Zoghlami et al., 2009) and for clonal discrimination (Regner et al., 2000; Riaz et al., 2002; Bertsch et al., 2003; Crespan, 2003; GonzàlesTechera et al., 2004; Hocquigny et al., 2004). On the contrary, some other researches have revealed the inability of SSRs to distinguish among grapevine clones (Crespan \& Milani, 2001; Imazio et al., 2002; Vignani et al., 2002; Ibànez et al., 2003). Imazio et al. (2002) recommended AFLP (Amplified Fragment Length Polymorphism) over the SSR approach when the goal is the definition of identity/diversity among different clones of the same variety, or among genetically closely related cultivars. Positive results in differentiating grapevine clones have been reported using AFLP markers (Vignani et al., 2002; Labra et al., 2004; Blaich et al., 2007; Stenkamp et al., 2009).

AFLPs is a technique based on the detection of genomic restriction fragment by PCR amplification and can be used for DNA of any origin or complexity without any prior knowledge of sequence. Indeed, this technique shows an ingenious combination of restriction fragment length polymorphism (RFLP) and PCR and is extremely useful in the detection of polymorphism between closely related genotypes, thus allowing the screening of higher numbers of anonymous loci compared to single-locus markers, such as SSRs. However, although simple in its methodology, the AFLP procedure shows some difficulties in data evaluation

*Corresponding author: E-mail: donato.antonacci@entecra.it [Tel: +39-080-8915711; Fax: +39-080-4512925]

Aknowledgements: This work was supported by the Project Vitivin-Valut, "Miglioramento qualitativo delle produzioni vitivinicole e dell'uva da tavola nel Mezzogiorno d'Italia", financed by the Ministry of Agricultural and Forestry Policy (MIPAF), Italy 
when carried out on gel due to the high number of bands produced and the low levels of polymorphism (almost all the bands obtained are monomorphic). In addition, the unknown origin of the clones and/or the different primer combinations could lead to results not always being comparable between different authors (Cervera et al., 1998; Fossati et al., 2001; Scott et al., 2001; Fanizza et al., 2003).

Aglianico is one of the most important grapevine (Vitis vinifera L.) cultivars grown in Southern Italy and is used mainly for the production of high quality red wines that are well known and appreciated all over the world. It is registered as Aglianico Nero (Varietal Code 002) in the Italian Register of Grape Varieties (IRGV) and represented in the cultivation areas by many biotypes, each of them included in various disciplines of production of Controlled Designation of Origin (DOC) and Controlled and Guaranteed Designation of Origin (DOCG) wines (https://www.politicheagricole.it/ DocumentiPubblicazioni/PQ elenco vini DOC DOCG. $\mathrm{htm})$. Aglianico biotypes are named according to the geographical area of cultivation and wine production, and the most common are Taurasi, Sannio, Cilento, Taburno and Vulture (Moio, 2004). However, Aglianico del Vulture is registered at the IRGV with a different code (Varietal Code 266), being considered as a different cultivar to Aglianico and not as a mere biotype. This is in contrast to what is reported by the Vitis International Variety Catalogue (VIVC; http://www.vivc.bafz.de/index.php) and by Costacurta et al. (2001), who reported Aglianico del Vulture and Aglianico Taurasi as synonyms of Aglianico Nero, while no information is available for the biotypes Sannio, Cilento and Taburno. The data in the literature do not report significant ampelographic (Violante \& Bordignon, 1962; Catalano et al., 1989) or molecular differences (Costacurta et al., 2001) between Aglianico and Aglianico del Vulture, which often are rather considered synonyms and then are used interchangeably to identify the cultivar.

This report aimed to characterise accessions of Aglianico, collected in Southern Italy (from Taurasi, Sannio, Cilento and Vulture), to provide further evidence that Aglianico Nero and Aglianico del Vulture Nero are synonyms by analysing ampelographic descriptors, SSRs and AFLP molecular markers and to verify the suitability of the AFLP method to distinguish molecular differences among accessions belonging to the same cultivar.

\section{MATERIALS AND METHODS \\ Plant materials}

Thirty-one Aglianico accessions (Table 1) were collected directly from private vineyards in Southern Italy. The different number of recovered accessions for each production area (Taurasi, Sannio, Cilento and Vulture) is representative of the real spread of the variety in the territory under investigation. All accessions were grafted onto 1103 Paulsen ( $V$. berlandieri $x V$. rupestris), spaced $2.5 \mathrm{~m}$ between rows $\mathrm{x}$ $1 \mathrm{~m}$ on the row, in an ex-situ collection of the experimental field of the Agricultural Research Council (C.R.A.), Research Unit of Turi (Bari - Italy). Each genotype was replicated ten times. Two registered and certified cultivars of Aglianico Nero (IRGV Code 002) and Aglianico del Vulture Nero (IRGV Code 266) were grown in the same experimental field and used as reference, for a total of 33 genotypes.

\section{Phenotype analysis}

Thirty ampelographic characters were measured on each accession during 2007, 2008 and 2009, following a list of descriptors developed by the Organisation Internationale de la Vigne et du Vin (OIV, 2009), including the preliminary minimal traits relative to shoots, leaves, bunches and berries (Table 1). Twenty readings per shoot and leaf descriptors were taken on ten plants. Bunch and berry measurements occurred at harvest, using 50 berries from 20 bunches.

Ampelographic data were used to create a similarity matrix, computed for interval measure (continuous) data with the SIMINT module, as implemented in NTSYS V2.1 software (Rohlf, 2000). The similarity matrix obtained was subjected to sequential agglomerative hierarchical nested (SAHN) clustering using unweighted pair-group method analysis (UPGMA) to generate a dendrogram, based on the DIST index, to present the morphological relationships between the accessions (Rohlf, 2000).

\section{Genotype analysis}

Total genomic DNA was extracted from freshly expanded leaves (at the phenological phase of flowering) using a commercial kit following the manufacturer's instructions (Dneasy Plant; Qiagen, Hilden, Germany), and the DNA was checked in terms of quality and quantity by $0.8 \%(\mathrm{w} / \mathrm{v})$ agarose gel electrophoresis and a spectrophotometer at 260 nm.

Thirteen SSR loci were analysed, six of them required by the EU project Genres CT96 N 81: VVS2, VVMD5, VVMD7, VVMD27, VrZAG62 and VrZAG79 (This et al., 2004), VVMD28, VVMD25 and VVMD32 (Bowers et al., 1999), ISV2, ISV3, ISV4 and VMCNG4b9 (Crespan, 2003). Multiplex PCR was conducted in an Eppendorf Mastercycler ${ }^{\circledR}$ EP thermocycler (Eppendorf, North America, Inc., New York, NY) in $20 \mu \mathrm{l}$ reactions containing $50 \mathrm{ng}$ of genomic DNA, 10 pmol of each forward and reverse primer, and QIAGEN Fast Cycling PCR Master Mix 2X (Qiagen, Hilden, Germany). Three or two primer pairs were carefully combined to co-amplify in a single reaction, and each forward primer was labelled with WellRED dyes, D2-PA (black), D3PA (green) or D4-PA (blue), at the 5' end (Proligo Primers \& Probes, Boulder, Colorado, USA). The cycling profile, according to the manufacturer's instructions in the QIAGEN Fast Cycling PCR kit, was: an initial heat activation step at $95^{\circ} \mathrm{C}$ for $5 \mathrm{~min}, 35$ cycles of denaturation at $98^{\circ} \mathrm{C}$ for $5 \mathrm{~s}$, annealing at $55^{\circ} \mathrm{C}$ for $30 \mathrm{~s}$ and extension at $68^{\circ} \mathrm{C}$ for $9 \mathrm{~s}$, and a final extension at $72 \mathrm{C}$ for $1 \mathrm{~min}$. The PCR products were analysed on a CEQ ${ }^{\mathrm{TM}} 8000$ Series Genetic Analysis System using a CEQ DNA Size Standard Kit 400 (Beckman Coulter S.p.A., Milan, Italy), and allele sizes were identified using automated fragment analysis.

AFLP analysis was conducted essentially as reported by Vos et al. (1995), with some modifications. Genomic DNA (150 ng) was double digested for $1 \mathrm{~h}$ with 20 units of EcoRI and 10 units of MseI. The DNA fragments were ligated with 3.5 units $\mathrm{T}_{4}$ ligase to an EcoRI adapter ( 5 pmol) and $\mathrm{Mse}$ I adapter $(50 \mathrm{pmol})$ in a final volume of $50 \mu \mathrm{l}$ at $15^{\circ} \mathrm{C}$ overnight. Twenty-five $\mu l$ of the resulting mixture were 


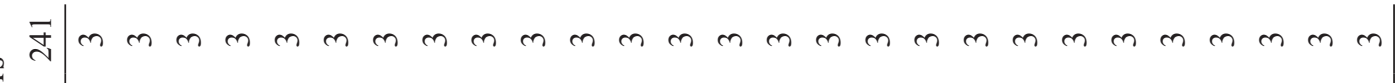
율 究



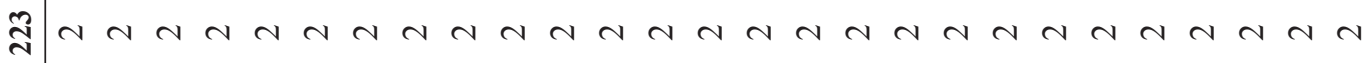



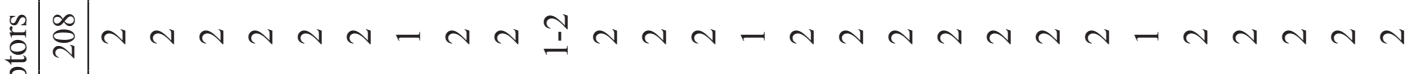
莺 ฮี 节

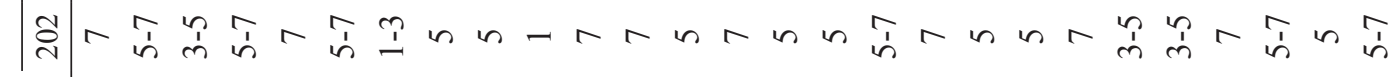

|

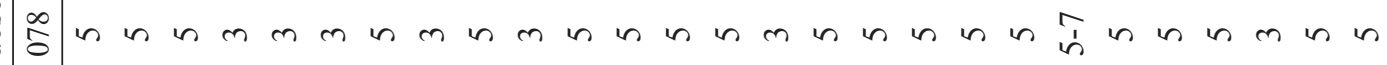

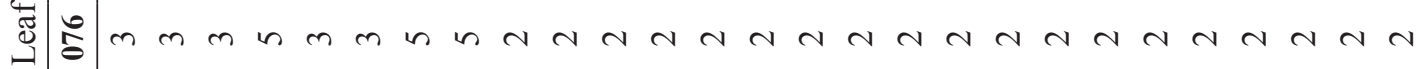

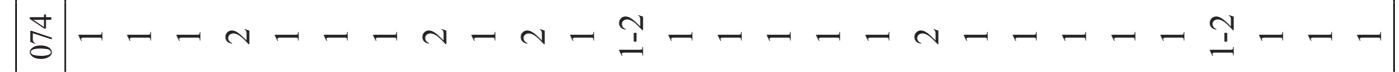

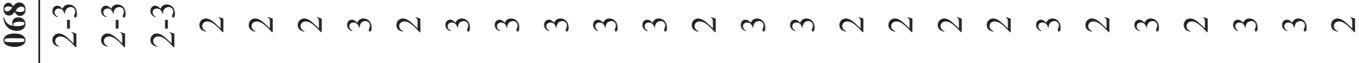

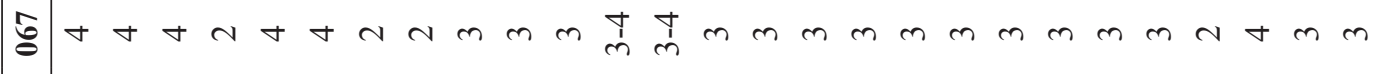

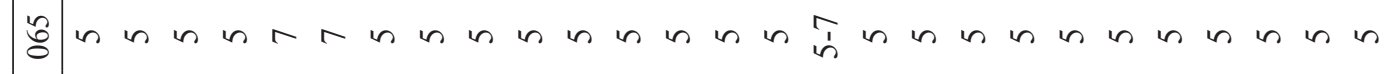
(5) ธ욤 


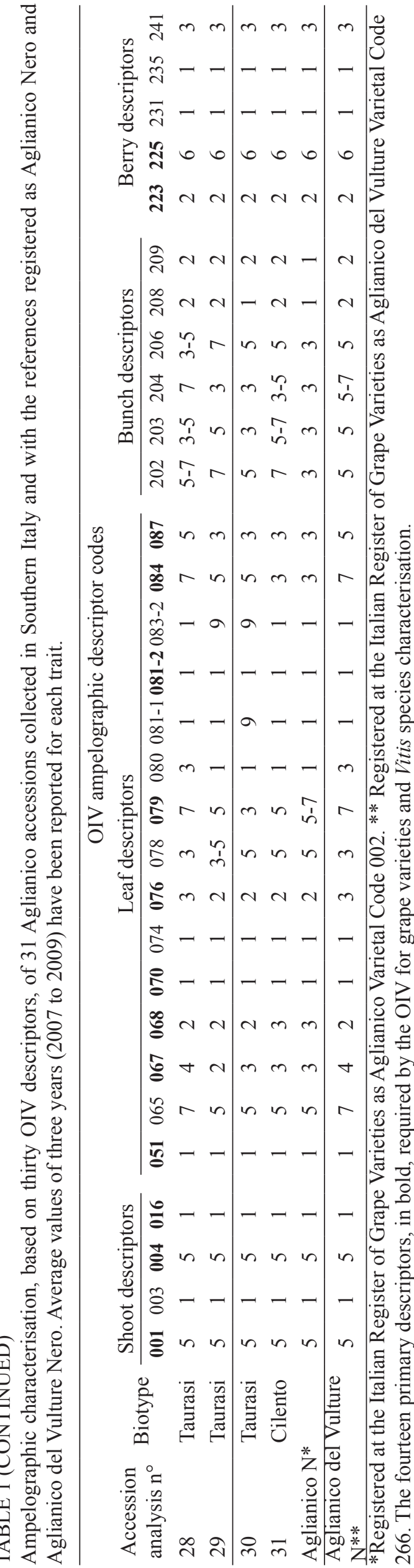

used as template in a pre-amplification reaction by adding 10x PCR buffer Fermentas, $25 \mathrm{mM} \mathrm{MgCl}, 250 \mathrm{ng}$ of primer EcoRI $(+1 \mathrm{~N})$ and $50 \mathrm{ng}$ of primer MseI $(+1 \mathrm{~N}), 10 \mathrm{mM}$ of each dNTP and 1.5 units of Taq DNA polymerase in a final volume of $45 \mu \mathrm{l}$. The PCR thermal conditions were: $3 \mathrm{~min}$ at $94^{\circ} \mathrm{C}, 21$ cycles of $30 \mathrm{~s}$ at $94^{\circ} \mathrm{C}, 1 \mathrm{~min}$ at $56^{\circ} \mathrm{C}$, and $1 \mathrm{~min}$ at $72^{\circ} \mathrm{C}$, with a final extension step of $7 \mathrm{~min}$ at $72^{\circ} \mathrm{C}$. The pre-amplification products were first checked on $1 \%(\mathrm{w} / \mathrm{v})$ agarose gels. Subsequently, the samples were diluted 1:10 or $1: 20$, based on their initial concentration. Four $\mu l$ of preamplification products were used as a template for selective amplification by adding 10x PCR buffer Fermentas, 25 $\mathrm{mM} \mathrm{MgCl}, 16 \mathrm{ng}$ primer EcoRI and $96 \mathrm{ng}$ primer MseI, $10 \mathrm{mM}$ dNTP each and 0.4 units Taq DNA polymerase in a final volume of $10 \mu \mathrm{l}$. EcoRI primers were labelled with fluorochromes FAM or HEX, and the following PCR conditions were used: $94^{\circ} \mathrm{C}$ for $3 \mathrm{~min}, 12$ cycles of $30 \mathrm{~s}$ at $94^{\circ} \mathrm{C}, 30 \mathrm{~s}$ at $65^{\circ} \mathrm{C}$ (the annealing temperature was reduced every cycle by $0.7^{\circ} \mathrm{C}$ ) and $1 \mathrm{~min}$ at $72^{\circ} \mathrm{C} ; 23$ additional cycles completed the selective amplification: $30 \mathrm{~s}$ at $94^{\circ} \mathrm{C}$, $30 \mathrm{~s}$ at $56^{\circ} \mathrm{C}$ and $1 \mathrm{~min}$ at $72^{\circ} \mathrm{C}$. The sequences of adaptors, pre-selective primers and selective primers are reported in Table 2. A total of 10 primer combinations with three selective nucleotides was used. The amplification products were first denatured at $94^{\circ} \mathrm{C}$ for $5 \mathrm{~min}$ and then separated by capillary electrophoresis on an ABI PRISM ® 3100 Avant Genetic Analyzer (Applied Biosystem), with GS ROX 500 as internal standard. AFLP electrophoregrams were acquired and analysed by Genographer 2.1.4 (http://sourceforge.net/ projects/genographer). Genographer allows the construction of a virtual gel with bands shaped on the base of peak height, resolution and mobility, and permits a thorough analysis of single fragments. Only clear and unambiguous bands were considered; weak and very low molecular weight bands were excluded from the analysis. Bands were scored by two different operators.

Calculations of total effective alleles $(\mathrm{Ne})$ (Kimura \& Crow 1964) and gene diversity value (GD) (Nei, 1973) were carried out as implemented in POPGENE V1.32 (Yeh et al., 1997). As proposed by Labra et al. (2004), the polymorphic information content (PIC) for the dominant marker AFLP was calculated as follows:

$\mathrm{PIC}=1-\Sigma\left(\mathrm{p}_{1}^{2}+\mathrm{p}_{0}^{2}\right)$

where $\mathrm{p}_{1}$ and $\mathrm{p}_{0}$ represent, respectively, the frequencies of $0 / 1$ alleles.

The average proportion of shared bands was calculated by averaging pairwise comparisons between accessions (Nei \& Li, 1979), and nucleotide diversity was estimated according to the method of Innan et al. (1999) for AFLP data.

Selectively amplified DNA polymorphic amplicons were used to create a rectangular matrix, where bands were scored as either present (1) or absent (0). A similarity matrix, based on the Dice index (Nei \& Li, 1979), was obtained and subjected to sequential agglomerative hierarchical nested (SAHN) clustering using unweighted pair-group method analysis (UPGMA), as implemented in NTSYS V2.1 software. A dendrogram was generated to present the phenetic relationships between the accessions. 
TABLE 2

Primers and adaptors used for AFLP analysis.

\begin{tabular}{ll}
\hline Name & Sequence \\
\hline EcoRI adaptor & 5'-CTCGTAGACTGCGTACC -3' \\
& 3'-CTGACGCATGGTTAA -5' \\
Mse I adaptor & 5'-GACGATGAGTCCTGAG -3' \\
& 3'-TACTCAGGACTCAT-5'
\end{tabular}

Preamplification selective primers

\begin{tabular}{ll} 
E1 & 5'-GACTGCGTACCAATTC+A -3' \\
M1 & 5'-GATGAGTCCTGAGTAA+C-3' \\
Amplification selective primers \\
E43* \\
E44* \\
E4'-CTCGTAGACTGCGTACC+ATC-3' \\
E46* ${ }^{*}$ '-CTCGTAGACTGCGTACC+ATA-3' \\
M48 & 5'-CTCGTAGACTGCGTACC+ATG-3' \\
M49 & 5'-CTCGTAGACTGCGTACC+ATT-3' \\
M50 & 5'-GATGAGTCCTGAGTAA+CAC-3' \\
M51 & 5'-GATGAGTCCTGAGTAA+CAG-3' \\
M59 & 5'-GATGAGTCCTGAGTAA+CAT-3' \\
M61 & 5'-GATGAGTCCTGAGTAA+CCA-3' \\
\hline
\end{tabular}

*Labelled. Selective nucleotides are reported in bold

\section{RESULTS}

\section{Phenotypic analysis}

The comparison of ampelographic data between Aglianico Nero and Aglianico del Vulture Nero showed morphological differences related mainly to the mature leaves and bunches, while complete uniformity was found for the descriptors for young shoots and berries (Table 1). Aglianico del Vulture Nero differed from Aglianico Nero in terms of larger leaf blades (OIV 065), orbicular vs. pentagonal shape (OIV 067), three lobes vs. five (OIV 068), and convex vs. straight teeth present on both sides (OIV 076), while the base of the petiole sinus was V-shaped vs. U-shaped (OIV 080) and there was a more intense presence of erect hairs on the lower side of the blades (OIV 084 and 087). Moreover, the Aglianico del Vulture Nero bunches in contrast to the Aglianico Nero bunches were, on average, scored to be longer (OIV 202), larger (OIV 203), and medium-dense vs. loose (OIV 204), with a longer peduncle (OIV 206) and a conical vs. a cylindrical shape (OIV 208).

Similarly, as reported in Table 1, ampelographic traits recorded on the rest of the accessions investigated reflected the overall differences that emerged between the two registered cultivars, particularly showing no difference for traits related to shoots and berries. Nine descriptors scored identical records for all the accessions. The young shoot tip was fully open (OIV 001), with two or fewer consecutive tendrils (number of consecutive tendrils - OIV 016), and the colour of the upper side of the blade of the fourth leaf (OIV 051) was green. The mature leaves showed a petiole sinus base not limited by the veins (OIV 81-2). As regards the berries, they were recorded as globose (shape - OIV 223) and blue-black (colour of skin - OIV 225), with no or low intensity of flesh anthocyanin coloration (OIV 231), soft flesh firmness (OIV 235) and complete seeds (formation of seeds - OIV 241).

We observed moderate variations in the other twentyone descriptors. As regards descriptors of the mature leaf, a comparison between the different accessions analysed in the present work with respect to the reference examples of Aglianico Nero and Aglianico del Vulture revealed a variable score. In particular, the mature leaf blade was wedge-shaped (OIV 067), circular or pentagonal as in the case of the certified variety. The shape of the teeth of the mature leaf (OIV 076) was straight on both sides, while some accessions had convex sides and others showed intermediate characteristics. We noted higher variability in the degree of opening/overlapping of the petiole sinus of the mature leaf (OIV 079): indeed, the reference variety showed both a closed/overlapped sinus and an open or closed sinus in other cases. On the contrary, only few accessions were recorded as having an overlapped sinus. The density of the prostrate hairs between the main veins on the lower side of the blade (OIV 084) ranged from low to medium. Finally, all the accessions showed a low or medium density of erect hairs on the main veins on the lower side of the blade (OIV 087), with the exception of accession 7 belonging to the Vulture biotype, which showed a high density, as in the case of the registered Aglianico del Vulture Nero.

Descriptors of bunches scored variable records among the accessions. The bunches were $8.0 \mathrm{~cm}$ to $20.0 \mathrm{~cm}$ long (OIV 202) and $4.0 \mathrm{~cm}$ to $16.0 \mathrm{~cm}$ wide (OIV 203), the density ranged from loose to medium (OIV 204), while the length of the peduncle of the primary bunches varied from $0.3 \mathrm{~cm}$ to $0.9 \mathrm{~cm}$ (OIV 206). All the bunches were cylindrical-conical (OIV 208), with no or one to two wings on the primary bunch.

Ampelographic data were used to obtain a dendrogram of similarity (Fig. 1) with the software NTSYS, using the distribution coefficient DIST and UPGMA algorithm. The dendrogram showed the formation of two main clusters and four sub-clusters. Both registered cultivars grouped to the third sub-cluster, while the fourth sub-cluster included the single Vulture accession 7, originating from the Vulture cultivation area. Despite the 30 phenotypic traits examined, accessions 9 and 26, 21 and 31, and 6 and 28 showed the same phenotype. In addition, the analysis showed a lack of clustering among the accessions on the basis of the registered cultivars, supporting the possibility that Aglianico Nero and Aglianico del Vulture Nero could be considered as the same variety.

\section{Genetic diversity}

The SSR profiles obtained were identified by comparison with the database of the Agricultural Research Council (C.R.A.) Research Unit of Turi (Bari - Italy), which contains the molecular profiles of more than 2000 accessions representing over 350 different wine and table grape varieties. SSR analysis revealed the total identity of all thirteen SSRs tested (Table 3) among all the accessions and registered cultivars examined. All the SSRs amplified a single locus profile. The loci VrZAG79, VrZAG62, VVMD7, VVS2, VVMD27 and VVMD5 are required by the EU project Genres CT96 
$\mathrm{N}^{\circ} 81$, "European network for grapevine genetic resources conservation and characterisation". Two of them, VrZAG62 and VVMD7, were homozygous, while the other eleven loci were heterozygous.

Conversely, the AFLP analysis, previously conducted on a panel of 16 wine grape cultivars, revealed the presence of different polymorphic fragments. This preliminary assay indicated the suitability of AFLP markers to distinguish among different cultivars, as reported by Vignani et al. (2002), Labra et al. (2004), Blaich et al. (2007) and Stenkamp et al. (2009). Ten different AFLP primer combinations produced 377 amplified fragments, of which 108 were polymorphic (mean $=10.8 \pm 4.39$ bands per primer combination) (Table 4). An example of an AFLP profile for the E44-M59 primer combination obtained with Genographer is reported in Fig. 2. Differences emerged in

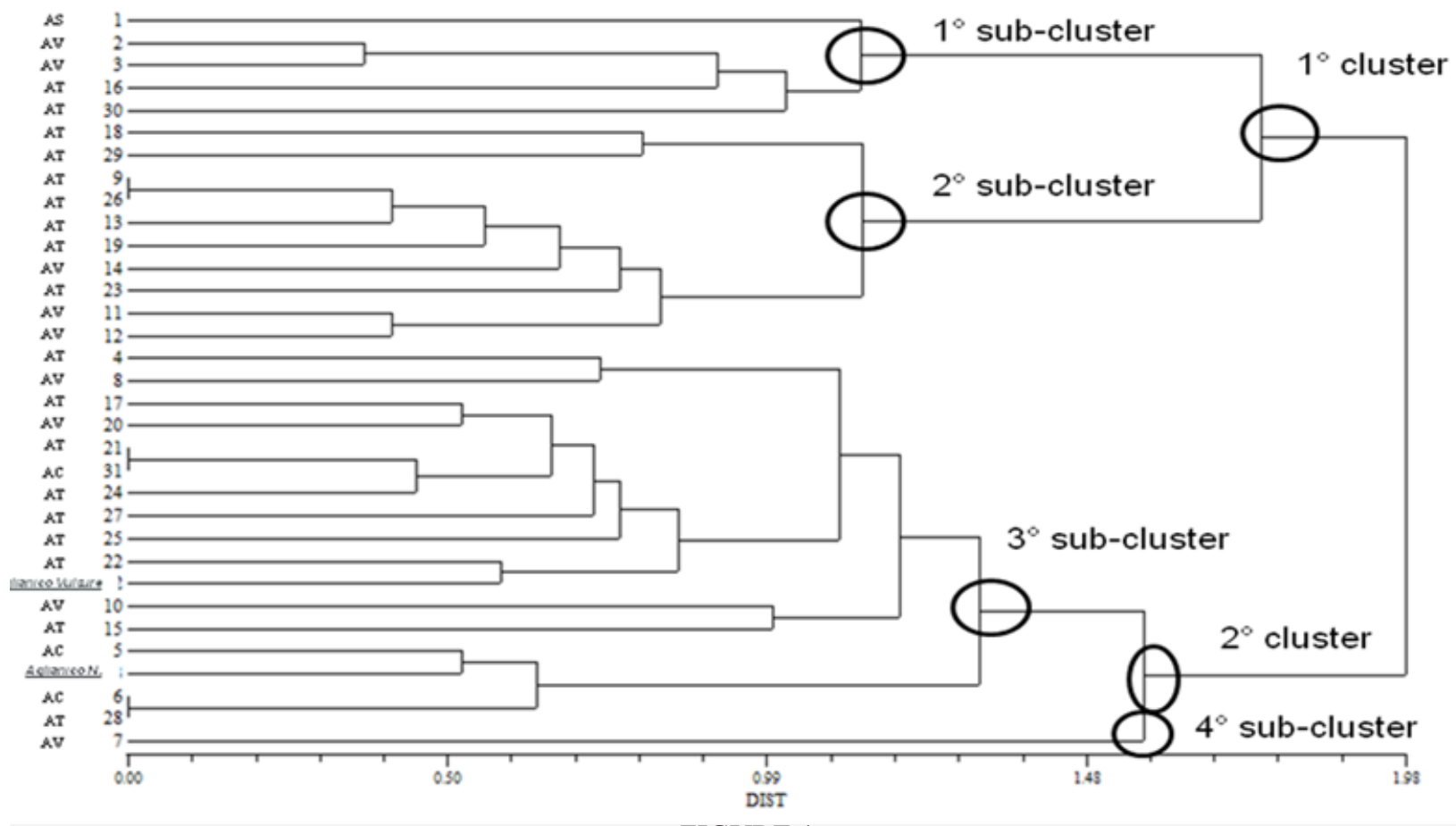

FIGURE 1

Similarity dendrogram of ampelographic data constructed using the unweighted pair group method with arithmetic means (UPGMA) as implemented in the NTSYS software based on the DIST distribution coefficient. The accessions ascribed to Aglianico del Vulture are shown in red, those ascribed to Aglianico Nero are shown in black, while the reference clones are highlighted in bold and underlined. $\mathrm{AC}=$ Aglianico del Cilento; $\mathrm{AS}=$ Aglianico del Sannio; AT = Aglianico del Taurasi; $\mathrm{AV}=$ Aglianico del Vulture.

TABLE 3

Allele size in base pairs of thirteen microsatellite markers performed on 31 Aglianico accessions collected in Southern Italy and with the references registered as Aglianico Nero and Aglianico del Vulture Nero.

\begin{tabular}{llc}
\hline SSR marker & & Allele size (bp) \\
\hline ISV3 & 134 & 146 \\
ISV4 & 171 & 259 \\
VVMD28 & 229 & 168 \\
VMCNG4b9 & 164 & 246 \\
VrZAG79* & 244 & 166 \\
ISV2 & 144 & - \\
VrZAG62* & 187 & - \\
VVMD7* & 238 & 155 \\
VVS2* & 151 & 188 \\
VVMD27* & 182 & 245 \\
VVMD5* & 231 & 263 \\
VVMD25 & 249 & 256 \\
VVMD32 & 250 & 2 \\
\hline
\end{tabular}

* SSR markers required by the EU project Genres CT96 $\mathrm{N}^{\circ} 81$ 
terms of fragments per primer combination, ranging from 25 to 61 . The mean polymorphism per primer combination was $28.9 \%+0.09$, with a range among primer combinations of four to 19 polymorphic bands per primer combination. The mean heterozygosity value, detected as the $\mathrm{N}_{\mathrm{e}}$ index, was $1.168 \pm 0.05$, while gene diversity (GD) showed a value of $0.110 \pm 0.04$. Finally, the PIC index scored a value of $0.063 \pm 0.04$, and the average proportion of shared bands was between $96.7 \%$ and $99.0 \%$ (mean $=97.9 \% \pm 0.01$ ), confirming the narrow genetic base investigated. A genomewide estimate of nucleotide diversity $(\pi)$ was obtained for each AFLP primer combination. Estimates varied from 0.492 to $1.703($ mean $=1.053 \pm 0.43)$.

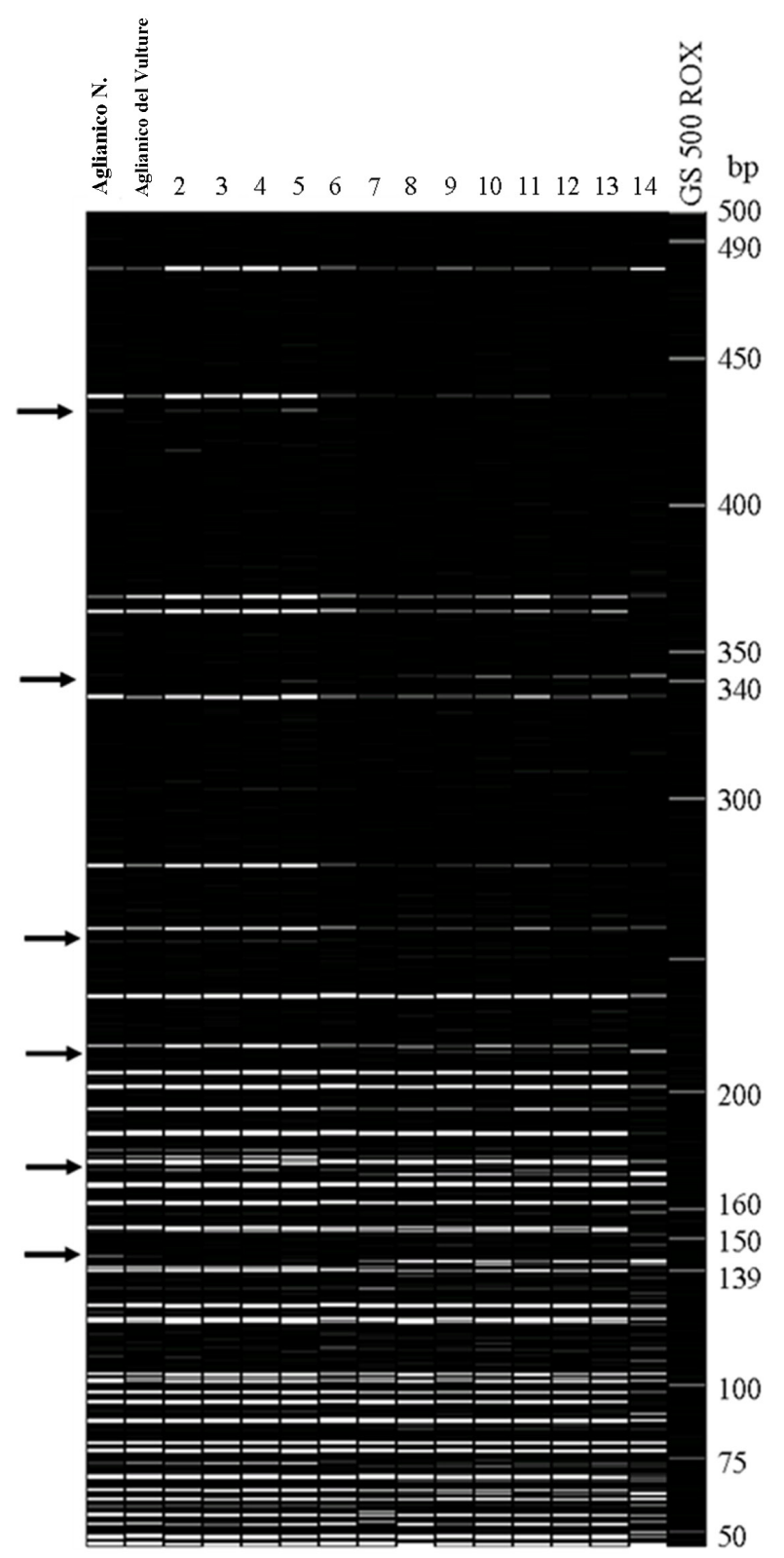

FIGURE 2

AFLP Genographer profile for the E44-M59 primer combination. Arrows indicate some relevant polymorphic bands among the references registered as Aglianico Nero, Aglianico del Vulture Nero and 13 Aglianico accessions (2-14).
The similarity matrix, obtained by measuring the Dice coefficient, produced a dendrogram for the AFLP data (Fig. 3 ). All the accessions grouped genetically close to each other, showing similarity coefficient values higher than 0.94 and, as in the case of the two registered cultivars Aglianico and Aglianico del Vulture, higher than 0.98. Consequently, a single cluster could be built, with the accessions 5 (biotype Cilento) and 7 (biotype Vulture) slightly distant from the rest of the samples. These results suggest a high genetic identity between the accessions and the registered cultivars. In addition, each accession was distinguished from the molecular point of view, unlike what was seen with the ampelographic analysis.

\section{DISCUSSION}

The occurrence of morphological differences, which is indeed frequent among genotypes of the same cultivar, is not reflected at the molecular level because of environmental influences on the expression of several phenotypic traits. This seemed to be the case in the two registered cultivars, Aglianico Nero and Aglianico del Vulture Nero, which showed few relevant differences in mature leaf and bunch records. Based on the outcome of the EU project Genres CT96 N 81, ampelographic descriptors have recently been modified to achieve more objectivity and limited sensitivity to environmental factors and agro-technologies (OIV, 2009). In this report, by considering only the OIV list of 14 primary descriptors (Table 1), the accessions and the registered cultivars Aglianico Nero and Aglianico del Vulture Nero showed no or little morphologic variation. When the analysis was implemented with other secondary descriptors, the ampelographic traits showed moderate variation. It has to be considered, however, that morphological parameters (especially those that refer to leaves) are influenced by environmental conditions and the age of the tissues, and this could determine phenotypic variation, also without genetic diversity (Barth et al., 2009). In order to restrict this aspect, the ampelographic data have been collected by the same operators and on the same plants under similar cultural condition. However, certain environmental pressures on the different accessions cannot be excluded. That is the reason why DNA-based molecular markers, which are not influenced by the environment, were examined in order to verify the genetic origin of the morphologically observed differences.

To perform the SSR analysis we considered 13 loci, including those SSRs required by the EU project Genres CT96 N 81. The results showed SSR monomorphic patterns at all the loci investigated for all the accessions and registered cultivars, in agreement with what was reported by Costacurta et al. (2001). SSR analysis allows us to confirm a synonymy between Aglianico Nero and Aglianico del Vulture Nero, previously not revealed by phenotypic data alone.

It is clear, however, that morphological or ampelographic data, although less subjective than in the past, may have an important role to play if supported by molecular analysis. An example is the case of Pinot varieties, which on the basis of SSR markers show an identical molecular profile for the white, gray and black varieties (Regner et al., 2000).

SSR markers are certainly an instrument with high 


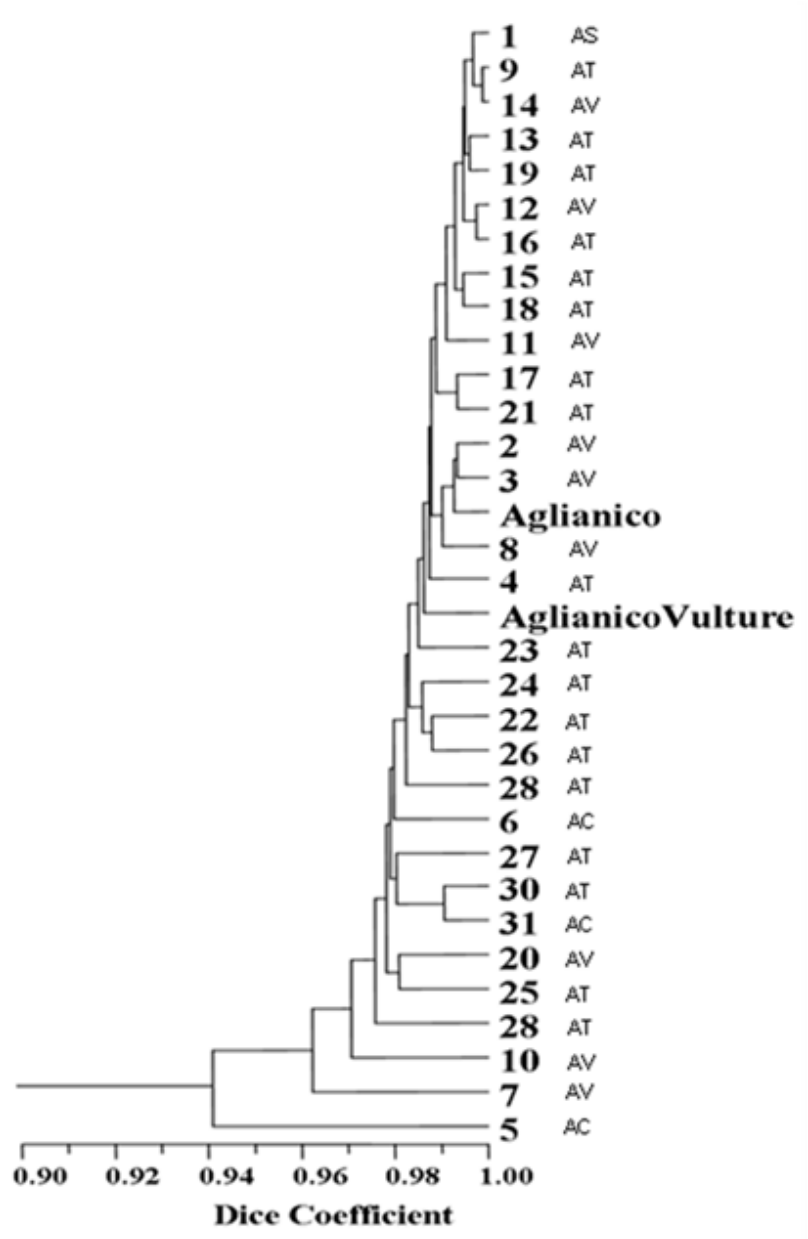

FIGURE 3

Unrooted dendrogram showing similarities of 31 Aglianico accessions and of the references registered as Aglianico

Nero and Aglianico del Vulture Nero, based on ten AFLP primer combinations constructed using the unweighted pair group method with arithmetic means (UPGMA) as implemented in NTSYS based on the Dice coefficient.

AC = Aglianico del Cilento; AS = Aglianico del Sannio; AT

= Aglianico del Taurasi; AV = Aglianico del Vulture .

inter-variety discriminatory ability (as proposed by Genres CT96 $\mathrm{N}^{\circ}$ 81), but they may not be sufficient to highlight intra-variety differences (grapevine clones). Indeed, as already reported, the use of AFLP markers instead of SSR ones is particularly suitable to define identity/diversity among different grapevine plants belonging to the same variety, or among genetically closely related cultivars. For these reasons, the analysis was integrated with AFLPs. In particular, the analysis showed evidence of low values of polymorphic fragments, genetic diversity indices and a high percentage of similarity among the accessions. As suggested by Hocquigny et al. (2004), a low molecular polymorphism among accessions belonging to a certain variety can be due to a monozygotic origin of the variety itself. Based on our results, this seems to be the case in relation to Aglianico Nero, whose vegetative propagation probably started from a unique single seedling that is also the common ancestor of Aglianico del Vulture Nero. Beside this, and taking into account that the experimentally calculated AFLP reproducibility is around 97.5\% (Hansen et al., 1999; Bonin et al., 2004), an error of $1.5 \%$ can be considered not significant and can be due to amplification errors, differences in peak intensities or human factors. Thus, genotypes differing by $1.5 \%$ on the total markers can be considered equal (Rotondi et al., 2003).

On the basis of these results, all the accessions included in this report, independently of the biotype, seem to belong to Aglianico Nero, and few morphological and molecular differences emerged from the comparison with Aglianico del Vulture Nero, confirming that a case of synonymy has occurred between these two cultivars and that, therefore, Aglianico Nero and Aglianico del Vulture Nero could be considered a unique cultivar.

Statistical analysis performed by NTSYS V2.1 software revealed a partial match between the morphological and AFLP molecular data. For example, the fingerprint of accession 7 revealed genetic diversity, thus confirming the greater phenotypic variability observed by ampelographic analysis. Indeed, it has to be noted that, as already reported in the literature, AFLP fingerprinting data are in agreement with the results obtained by ampelographic analyses when a high number of morphological characters are considered (Meneghetti et al., 2010).

However, it is still not clear if two accessions/clones showing some morphological differences, but identical molecular patterns, can be considered as belonging to the same cultivar, and this aspect currently is under discussion. Pelsy et al. (2010) reported that, traditionally, clones are attributed to a variety on the basis of several common ampelographic traits, although phenotypic variations between clones of the same variety are often observed and accepted.

Grapevine cultivars are often spread via vegetative propagation and this leads to the diffusion of numerous genetically identical copies of a specific plant. During this process, somatic mutation could occur and this results in a plant characterised by unique genomic traits that could lead to a unique phenotype. A considerable proportion of the morphological diversity in grape germplasm is the results of spontaneous somatic mutations fixed through vegetative propagation rather than by segregating polymorphism. Identifying the causal genetic variants underlying phenotypic variation among clones will be a challenging task, for which deep re-sequencing will be required (Myles et al., 2011).

The publication of the grapevine genome sequences of a highly inbred line of Pinot noir PN40024 (Jaillon et al., 2007) and a commercial clone of Pinot noir (Velasco et al., 2007) has provided a new generation of molecular tools in the development of new molecular markers (SNP) that are useful to better understand genotypic-phenotypic relationships. In fact, the collection of phenotypic data requires more careful characterisation at the morphological, biochemical, physiological or pathological and environmental response levels. Open databases with these phenotypic and genotypic data are required, as well as more efficient ways to store and exchange biological materials representing all the available genetic diversity (Martínez-Zapater et al., 2010).

Therefore, it would be important to establish and standardise a molecular method that allows researchers to 
TABLE 4

Descriptive statistics of AFLP markers performed on 31 Aglianico accessions collected in Southern Italy and with the references registered as Aglianico Nero and Aglianico del Vulture Nero.

\begin{tabular}{|c|c|c|c|c|c|c|c|c|}
\hline \multirow[t]{2}{*}{$\begin{array}{l}\text { Primer } \\
\text { combination }\end{array}$} & \multirow{2}{*}{$\begin{array}{c}\text { Total bands } \\
\text { amplified } \\
\text { n. }\end{array}$} & \multicolumn{2}{|c|}{ Polymorphic bands } & \multirow{2}{*}{$\begin{array}{c}\text { Effective } \\
\text { alleles } \\
\mathrm{N}_{\mathrm{e}}\end{array}$} & \multirow{2}{*}{$\begin{array}{c}\text { Gene } \\
\text { diversity } \\
\text { GD }\end{array}$} & \multirow{2}{*}{$\begin{array}{c}\text { Polymorphic } \\
\text { information } \\
\text { content } \\
\text { PIC }\end{array}$} & \multirow{2}{*}{$\begin{array}{c}\text { Average } \\
\text { proportion } \\
\text { of shared } \\
\text { bands } \\
\% \\
\end{array}$} & \multirow{2}{*}{$\begin{array}{l}\text { Nucleotide } \\
\text { diversity } \\
\pi(\mathrm{x} \mathrm{1000)}\end{array}$} \\
\hline & & $\mathrm{n}$. & $\%$ & & & & & \\
\hline E43-M48 & 61 & 19 & 31.1 & 1.167 & 0.105 & 0.043 & 98.1 & 0.959 \\
\hline E43-M50 & 27 & 4 & 14.8 & 1.087 & 0.053 & 0.022 & 99.0 & 0.604 \\
\hline E43-M51 & 45 & 16 & 35.6 & 1.189 & 0.120 & 0.150 & 98.0 & 0.533 \\
\hline E44-M48 & 34 & 11 & 32.4 & 1.185 & 0.118 & 0.079 & 97.4 & 0.492 \\
\hline E44-M59 & 36 & 12 & 33.3 & 1.242 & 0.142 & 0.074 & 96.7 & 0.995 \\
\hline E44-M61 & 31 & 12 & 38.7 & 1.219 & 0.136 & 0.050 & 97.7 & 1.107 \\
\hline E45-M61 & 30 & 11 & 36.7 & 1.198 & 0.126 & 0.105 & 96.7 & 1.281 \\
\hline E46-M49 & 25 & 7 & 28.0 & 1.185 & 0.110 & 0.047 & 97.8 & 1.673 \\
\hline E46-M59 & 53 & 8 & 15.1 & 1.087 & 0.054 & 0.034 & 98.8 & 1.179 \\
\hline E46-M61 & 35 & 8 & 22.9 & 1.118 & 0.077 & 0.022 & 98.9 & 1.703 \\
\hline Total & 377 & 108 & & & & & & 1.005 \\
\hline Mean & 37.7 & 10.8 & 28.9 & 1.168 & 0.110 & 0.063 & 97.9 & 1.053 \\
\hline SD & 11.71 & 4.39 & 0.09 & 0.05 & 0.04 & 0.04 & 0.01 & 0.43 \\
\hline
\end{tabular}

obtain molecular profiles of a comparable range to be used for clonal discrimination. This work provides an important molecular contribute to study the genetic variability and identification of grape clones. We propose an automated AFLP method, with a standardisation of restriction enzymes and primer combinations, the use of a capillary sequencer and software to increase the reproducibility and discriminatory power of the traditional method, and with the support of phenotypic characterisation, in order to provide a technique that is less laborious and that will be comparable among different laboratories for clone identification.

\section{LITERATURE CITED}

Barth, S., Forneck, A., Verzeletti, F., Blaich, R. \& Schumann, F., 2009 Genotypes and phenotypes of an ex situ Vitis vinifera ssp sylvestris (Gmel) Beger germplasm collection from the Upper Rhine Valley. Genet. Resour. Crop Evol. 56, 1171-1181.

Bertsch, C., Kieffer, F., Triouleyre, C., Butterlin, G., Merdinoglu, D. \& Walter, B., 2003. Molecular profiling of Vitis vinifera Chardonnays obtained by somatic embryogenesis. J. Int. Sci. Vigne Vin 37, 223-227.

Blaich, R., Konradi, J., Rühl, E. \& Forneck, A., 2007. Assessing genetic variation among Pinot noir (Vitis vinifera $\mathrm{L}$ ) clones with AFLP markers. Am. J. Enol. Vitic. 58 (4), 526-529.

Bonin, A., Bellemain, E., Bronken Eidesen, P., Pompanon, F., Brochmann, C. \& Taberlet, P., 2004. How to track and assess genotyping errors in population genetics studies. Mol. Ecol. 13 (11), 3261-3273.

Bowers, J.E., Dangl, G.S. \& Meredith, C.P., 1999. Development and characterization of additional microsatellite DNA markers for grape. Am. J. Enol. Vitic. 50, 243-246.

Catalano, V., Cersosimo, A. \& Stramaglia L., 1989. Aglianico del Vulture. In: Ministero dell'Agricoltura e delle Foreste (ed.). Principali vitigni da vino coltivati in Italia, Vol. I. Roma, Italy. pp. 145-159.
Cervera, M.T., Cabenaz, J.A., Sancha, J.C., Martinez-de-Toda, F. \& Martinez-Zapater, J.M., 1998. Application of AFLPs to the characterization of grapevine Vitis vinifera L. genetic resources: a case study with accessions from Rioja (Spain). Theor. Appl. Genet. 97, 51-59.

Costacurta, A., Calò, A., Crespan, M., Milani, N., Giust, M., Aggio, L., Carraio, R., Di Stefano, R., Giordano, M., Rotundo, A., Marone, F., Martelli, S., D’Angelo, D. \& Mastroberardino, P., 2001. La caratterizzazione e selezione clonale di Aglianico e Aglianicone. Proc. Accademia Italiana della Vite e del Vino, 24-25 May, Avellino (Italy).

Crespan, M., 2003. Evidence on the evolution of polymorphism of microsatellite markers in varieties of Vitis vinifera L. Theor. Appl. Genet. $108,231-237$.

Crespan, M. \& Milani, N., 2001. The Muscats. a molecular analysis of synonyms, homonyms and genetic relationships within a large family of grapevine cultivars. Vitis 40, 23-30.

Fanizza, G., Chaabane, R., Ricciardi, L. \& Resta, P., 2003. Analysis of a spontaneous mutant and selected clones of cv. Italia (Vitis vinifera) by AFLP markers. Vitis 42(1), 27-30.

Fossati, T., Labra, M., Castiglione, S., Failla, O., Scienza, A. \& Sala, F., 2001. The use of AFLP and SSR molecular markers to decipher homonyms and synonyms in grapevine cultivars: the case of the varietal group known as chiave. Theor. Appl. Genet. 102, 200-205.

Gonzàles-Techera, A., Jubany, S., Ponce de Lèon, I., Boido, E., Dellacassa, E., Carrau, F.M., Hinrichsen, P. \& Gaggero, C., 2004. Molecular diversity within clones of cv Tannat (Vitis vinifera). Vitis 43, 179-185.

Hansen, M., Kraft, T. \& Christiansson, M., 1999. Evaluation of AFLP in Beta. Theor. Appl. Genet. 98, 845-852.

Hocquigny, S., Pelsy, F., Dumas, V., Kindt, S., Heloir, M.C. \& Merdinoglu, D., 2004. Diversification within grapevine cultivars goes through chimeric states. Genome 47, 579-589. 
Ibànez, J., De Andrès, M.T., Molino, A. \& Borrego, J., 2003. Genetic study of key Spanish grapevine varieties using microsatellite analysis. Am. J. Enol. Vitic. 54, 22-30.

Imazio, S., Labra, M., Grassi, F., Winfield, M., Bardini, M. \& Scienza, A., 2002. Molecular tools for clone identification: the case of the grapevine cultivar “Traminer". Plant Breeding 121, 531-535.

Innan, H., Terauchi, R., Kahl, G. \& Tajima, F., 1999. A method for estimating nucleotide diversity from AFLP data. Genetics 151, 1157-1164.

Jahnke, G., Màjer, J., Lakatos, A., Györffyné Molnàr, J., Deàk, E., Stefanovits-Bànyai, E. \& Varga, P., 2009. Isoenzyme and microsatellite analysis of Vitis vinifera L. varieties from the Hungarian grape germplasm. Sci. Hort. 120, 213-221.

Jaillon, O., Aury, J.-M., Noel, B., Policriti, A., Clepet, C., Casagrande, A., Choisne, N., Aubourg, S., Vitulo, N., Jubin, C., Vezzi, A., Legeai, F., Hugueney, P., Dasilva, C., Horner, D., Mica, E., Jublot, D., Poulain, J., Bruyere, C., Billault, A., Segurens, B., Gouyvenoux, M., Ugarte, E., Cattonaro, F., Anthouard, V., Vico, V., Del Fabbro, C., Alaux, M., Di Gaspero, G., Dumas, V., Felice, N., Paillard, S., Juman, I., Moroldo, M., Scalabrin, S., Canaguier, A., Le Clainche, I., Malacrida, G., Durand, E., Pesole, G., Laucou, V., Chatelet, P., Merdinoglu, D., Delledonne, M., Pezzotti, M., Lecharny, A., Scarpelli, C., Artiguenave, F., Pé, E., Valle, G., Morgante, M., Caboche, M., Adam-Blondon, A.-F., Weissenbach, J., Quétier, F. \& Wincker, P., 2007. The grapevine genome sequence suggests ancestral hexaploidization in major angiosperm phyla. Nature, 449:463468

Kimura, M. \& Crow, J.F., 1964. The number of alleles that can be maintained in a finite population. Genetics 49, 725-738.

Labra, M., Imazio, S., Grassi, F., Rossoni, M. \& Sala, F., 2004. Vine-1 retrotransposon-based sequence-specific amplified polymorphism for Vitis vinifera L genotyping. Plant Breeding 123, 180-185.

Martínez-Zapater, J.M., Carmona, M.J., Díaz-Riquelme, J., Fernández, L. \& Lijavetzky, D., 2010. Grapevine genetics after the genome sequence: challenges and limitations. Aust. J. Grape Wine Res. 16, 33-46.

Meneghetti, S., Costacurta, A., Frare, E., Da Rold, G., Migliaro, D., Morreale, G., Crespan, M., Sotés, V. \& Calò, A., 2010. Clones identification and genetic characterization of Garnacha grapevine by means of different PCR-derived marker systems. Mol Biotechnol. DOI: 10.1007/s12033-0109365-3.

Myles, S., Boykob, A.R., Owense, C.L., Browna, P.J., Grassif, F., Aradhyag, M.K., Prinsg, B., Reynoldsb, A., Chiah, J., Wareh, D., Bustamanteb, C.D. \& Bucklera, E.S., 2011. Genetic structure and domestication history of the grape. PNAS. DOI: 10.1073/pnas.1009363108.

Moio, L., 2004. Colori, odori ed enologia dell'Aglianico. Sette anni di sperimentazione e ricerca enologica in Campania. Regione Campania, Assessorato Agricoltura (Se.S.I.R.C.A.) (ed.), Napoli, Italia, pp 109-184.

Nei, M., 1973. Analysis of gene diversity in subdivided populations. Proc. Natl. Acad. Sci. USA 70, 3321-3323.

Nei, M. \& Li, W.H., 1979. Mathematical model for studying genetic variation in terms of restriction endonucleases. Proc. Natl. Acad. Sci. USA 76, 5273-5296.

OIV, 2009. $2^{\text {nd }}$ edition of the OIV descriptor list for grape varieties and Vitis species. Organisation Internationale de la Vigne et du Vin, Paris, France International Plant Genetic Resources Institute, Rome, Italy (www.oiv.org).

Pelsy, F., Hocquigny, S., Moncada, X., Barbeau, G., Forget, D., Hinrichsen, P. \& Merdinoglu, D., 2010. An extensive study of the genetic diversity within seven French wine grape variety collections. Theor. Appl. Genet. $120,1219-1231$
Regner, F., Stadlbauer, A., Eisenheld, C. \& Kaserer, H., 2000. Genetic relationships among Pinots and related cultivars. Am. J. Enol. Vitic. 51, $7-14$.

Rohlf, F.J., 2000. NTSYS-pc numerical taxonomy and multivariate analysis system, version 2.1. Exeter Software, Setauket, N.Y.

Riaz, S., Garrison, K.E., Dangl, G.S., Boursiquot, J.M. \& Meredith, C.P., 2002. Genetic divergence and chimerism within ancient asexually propagated winegrape cultivars. J. Am. Soc. Hortic. Sci. 127, 508-514.

Rotondi, A., Magli, M., Riccioloni, C. \& Baldoni, L., 2003. Morphological and molecular analyses for the characterization of a group of Italian olive cultivars. Euphytica 132, 129-137.

Scott, K.D., Ablett, E.M., Lee, L.S. \& Henry, R.J., 2001. AFLP markers distinguishing an early mutant of Flame Seedless grape. Euphytica 113, 245-249.

Stenkamp, S.H.G., Becker, M.S., Hill, B.H.E., Blaich, R. \& Forneck, A., 2009. Clonal variation and stability assay of chimeric Pinot Meunier (Vitis vinifera L) and descending sports. Euphytica 165, 197-209.

This, P., Jung, A., Boccacci, P., Borrego, J., Botta, R., Costantini, L., Crespan, M., Dangl, G.S., Eisenheld, C., Ferreira-Monteiro, F., Grando, M.S., Ibanez, J., Lacombe, T., Laucou, V., Magalhaes, R., Meredith, C.P., Milani, N., Peterlunger, E., Regner, F., Zurlini, L. \& Maul, E., 2004. Development of a standard set of microsatellite references alleles for identification of grape cultivars. Theor. Appl. Genet. 109, 1448-1458.

Velasco, R., Zharkikh, A., Troggio, M,. Cartwright, D.A., Cestaro, A., Pruss, D., Pindo, M., FitzGerald, L.M., Vezzulli, S., Reid, J., Malacarne, G., Iliev, D., Coppola, G., Wardell, B., Micheletti D., Macalma, T., Facci, M., Mitchell, J.T., Perazzolli, M., Eldredge, G., Gatto, P., Oyzerski, R., Moretto, M., Gutin, N., Stefanini, M., Chen, Y., Segala, C., Davenport, C., Dematte, L., Mraz, A., Battilana, J., Stormo, K., Costa, F., Tao, Q., SiAmmour, A., Harkins, T., Lackey, A., Perbost, C., Taillon, B., Stella, A., Solovyev, V., Fawcett, J.A., Sterck, L., Vandepoele, K., Grando, S.M., Toppo, S., Moser, C., Lanchbury, J., Bogden, R., Skolnick, M., Sgaramella, V., Bhatnagar, S.K., Gutin, A., Van de Peer, Y., Fontana, P.,Salamini, F., Viola, R., 2007. A high quality draft consensus sequence of the genome of a heterozygous grapevine variety. PLoS ONE 2(12), e1326. DOI: 10.1371/ journal.pone.0001326.

Vignani, R., Scali, M. \& Masi, E., 2002. Genomic variability in Vitis vinifera L "Sangiovese" assessed by microsatellite and non-radioactive AFLP test [Online]. Electronic Journal of Biotechnology 5 (1), 1-11. Available; http.// www.ejborg/content/vol5/issue1/full/2

Violante, C. \& Bordignon, S., 1962. In: Ministero dell'Agricoltura e delle Foreste (ed.). Principali vitigni da vino coltivati in Italia, Vol. III. Roma, Italy. pp. 1-10.

Vos, P., Hogers, R., Bleeker, M., Reijans, M., Van de Lee, T., Hornes, M., Frijters, A., Pot, J., Peleman, J., Kuiper, M. \& Zabeau, M., 1995. AFLP: a new technique for DNA fingerprinting. Nucl. Acids Res. 23, 4407-4414.

Yeh, F.C., Yang, R.C., Boyle, T.J.B., Ye, Z.H. \& Mao, J.X., 1997. POPGENE, the user-friendly shareware for population genetic analysis [Online]. Molecular Biology and Biotechnology Centre, Univ. Alberta, Edmonton, AB, Canada. Available: http://www.ualberta.ca/ fyeh/

Zoghlami, N., Riahi, L., Laucou, V., Lacombe, T., Mliki, A., Ghorbel, A. \& This, P., 2009. Origin and genetic diversity of Tunisian grapes as revealed by microsatellite markers. Sci. Hort. 120, 479-486. 